\title{
The healthy and sustainable growth of medicinal and aromatic plants through nanotechnology: A review
}

\author{
Kuntal Das \\ Dept. of Pharmacognosy and Phytochemistry, Krupanidhi College of Pharmacy, Carmelaram Post, Varthur Hobli, Bangalore-560035, KA, India
}

\section{Article Info}

Article history

Received 19 January 2021

Revised 23 February 2021

Accepted 24 February 2021

Published Online 30 March 2021

\section{Keywords}

Biomass

Herbals nanotechnology

MAPs

Nanoparticles

Nanofertilizers

\begin{abstract}
India is a land of agriculture with diverse climatic conditions. Therefore, domestication of the medicinal and aromatic plants (MAPs) from the forest zone through standardized cultivation practices is most essential. Good agricultural practices (GAP) as per standard guideline provide healthy growth of the plants with higher biomass yield. In spite of that, adaptation of any new technology in such cultivation boosts the yield synergistically. Nanoscience is such new technology by which many impossible domains became possible with easiest way. Of late, nanofertilization is such a new revolution in agriculture science, with that many states in India got their economic strength through effective cultivation of MAPs. Nanofertilization helps in improving nutrient uptakes by the plant roots, accumulate them in the plant body for many metabolic functioning, helps in sustain increase of plant growth and also leads to enhancement of higher amount of phytochemicals accumulation in plant body. Furthermore, reduced chemical spreads, nutrient losses in fertilisation, and enhanced biomass output through pest and nutrient control, among other things, enable some significant encumbrance of nanotechnology to be implemented. Ultimately, the article highlighted the types of modern applications of nanofertilizers and its beneficial impact on MAPs in improved quality and efficiency of canopy yield and yield attributes.
\end{abstract}

\section{Introduction}

The study of managing matter on an atomic and molecular scale is known as nanotechnology. It is a very diverse concept and recently it is also used in medicine to cure many diseases. Two of the elements, americium and curium, were patented in 1964 by Glenn T. Seaborg, a Nobel Laureate in Chemistry. This was the start of atomically and molecularly created matter being patented. Norio Tanigutchi, a Professor at Tokyo Science University, developed the term nanotechnology in 1974 to describe precision manufacturing on a nanoscale scale. Particles in the $10 \mathrm{~nm}^{-1} \mu \mathrm{m}$ range are commonly used in nanotechnology (Bayda et al., 2019).

In addition to the current COVID-19 pandemic situation, the global economy has been dramatically affected by all sectors, including agriculture and food production industries, by the global burgeon in human population and rapid urbanization. As a result, farmers around the world are faced with the onerous burden of feeding more mouths from agricultural grounds that are fast dwindling. Scientifically, it is clear that our planet's fertile land is fast depleting, and food production has been declining over the past decade. Food production will not be sufficient to meet the expanding population's need in coming years but people can contemplate a self sustainable world through only

Corresponding author: Dr. Kuntal Das

Professor, Department of Pharmacognosy and Phytochemistry, Krupanidhi College of Pharmacy, Carmelaram Post, Varthur Hobli, Bangalore-560035,KA, India

E-mail: drkkdsd@gmail.com

Tel.: +91-9632542846

Copyright () 2021 Ukaaz Publications. All rights reserved.

Email: ukaaz@yahoo.com; Website: www.ukaazpublications.com one field, i.e., agriculture. Though, the availability of land and water resources is limited but the productivity in agricultural sector drastically increased with the extensive usage of modern technologies. Of late, nano application is among the revolutionary technology in agriculture domain. Nanotechnology has the potential to improve agricultural productivity by genetically improving plants and delivering genes and drug molecules to specific sites in MAPs at the cellular level using appropriate techniques and sensors in precision agriculture, natural resource management, and efficient agrochemical delivery systems (e.g., fertilizers and pesticides, food processing, packaging and food system security). Controlling nutrient release and availability, characterization and weathering of soil minerals, soil properties, and nutrient ion transport in soil plant systems, water conservation with treatment, and efficient management of soil health, including ground water pollution, are all possible applications of nanotechnology. Not only that, it also contributes in a broad way to ensure security of food, health, energy and environmental safety for the ever growing unabated Indian population (Figure 1). Nanotechnology has recently been discovered to have potential uses in the weathering and development of soil minerals, nutrient ion transport in soil plant systems, zeoponics, and the emission of dusts and aerosols from agricultural soils and their nature (Das, 2005; Mukhopadhyay et al., 2009).

Agriculture is India's most stable sector since it generates and supplies raw materials for the food and food processing sectors. Due to the cultural conditions, the alteration in the MAPs growth and productivity are widely varied in the recent year (Mukhopadhyay, 2014). The most important challenges are depletion of natural resources, 
deterioration of soil nature, declining productivity resurgence of new pests and diseases, global warming and climate change that affects in sustainable development. Therefore, fertilization is one of the important activities that remain fundamental concern in improvement of soil fertility. But, the over dose of fertilizers may show the unwanted impacts, viz., soil salinity, expansion of heavy metals, increment of nitrate, high enrichment of minerals in water, and even produces green house effect due to air contamination by nitrogen and sulfur (Savci, 2012; Fernández-Luqueño et al., 2014). Hence, a novel multidimensional nanotechnology plays an immense role and potential impact in the fertilization domain of agriculture field by facilitating the slow and constant release of nutrients. The technology also decreases the loss of nutrients and improves the efficiency of the nutrients application in MAPs and apparently contributes significant enhancement in quality and quantity of biomass yields with minimal dependency on environment (Liu and Lal, 2015). There are some important differences between nanofertilizers along with conventional or traditional fertilizers. The beneficial impact of nanotechnology is mainly due to the properties of nanoparticles (NPs). Nanoparticles can be created chemically or physically, but they can also be created utilising microbes, enzymes, fungus, and plants or plant extracts, all of which are environmentally friendly (Konishi and Uruga, 2007; Ahmad et al., 2011). In comparison to the inside of the nanoparticles, there are more atoms on the surface of the nanoparticles. This results in a high surface-to-volume ratio, which results in increased charge density and reactivity of nanoparticles. Importantly, silver, gold, alloy, magnetic nanoparticles are some important types which used in herbal field (Figure 2). Silver nanoparticles are effective against mainly bacteria, viruses and acts as potential antimicrobial agent (Rai et al., 2009). In immunochemical research, gold nanoparticles are employed to identify protein interactions, DNA finger printings for DNA identification, cancer stem cell detection, etc. (Tomar and Garg, 2013). Alloy nanoparticles contain structural properties among that bimetallic alloy nanoparticles show more efficiency than normal one in terms of improved electronic, optical and catalytic performances (Hasan, 2015) whereas, magnetic nanoparticles are useful for DNA analysis, targeted cancer treatment, stem cell manipulations, etc., example, $\mathrm{Fe}_{3} \mathrm{O}_{4}$ (magnetite) and $\mathrm{Fe}_{2} \mathrm{O}_{3}$ (maghemite) which are biocompatible (Fan et al., 2009).

In the nanofertilizer, the most important useful method is nanobiofertilizer which is a conjugate preparation and combinatorial practical application of nano and biofertilizers (including soil beneficial microbes) (Figure 3). The application of nanobiofertilizer is improvement and sustainable crop productivity with environmental safety (Kalia and Kaur, 2019). The contribution of nanotechnology to the development of nano fertilizer, as well as its uses and functions in soil, is the emphasis of this publication.

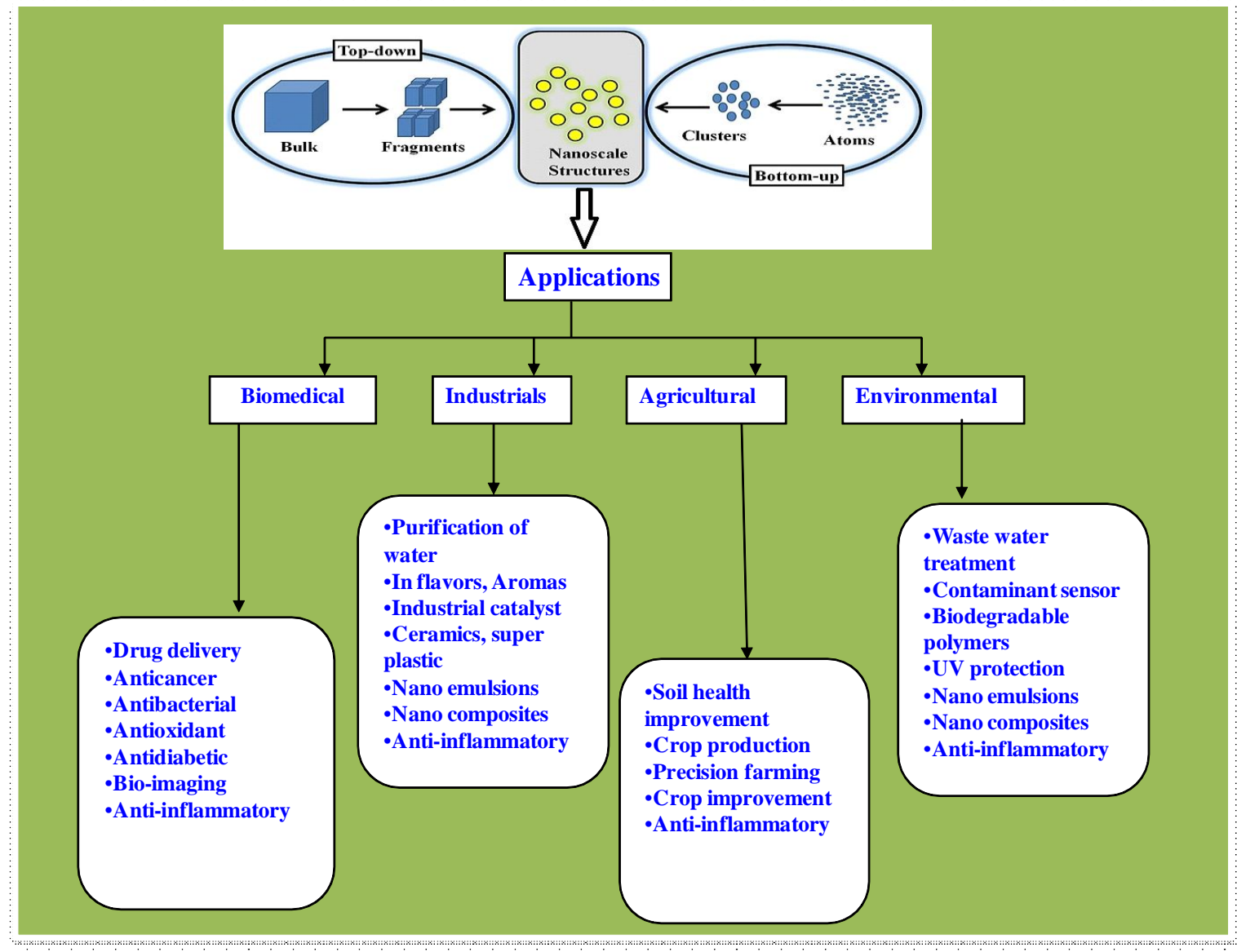

Figure 1: Application of nanoparticles in various fields. 


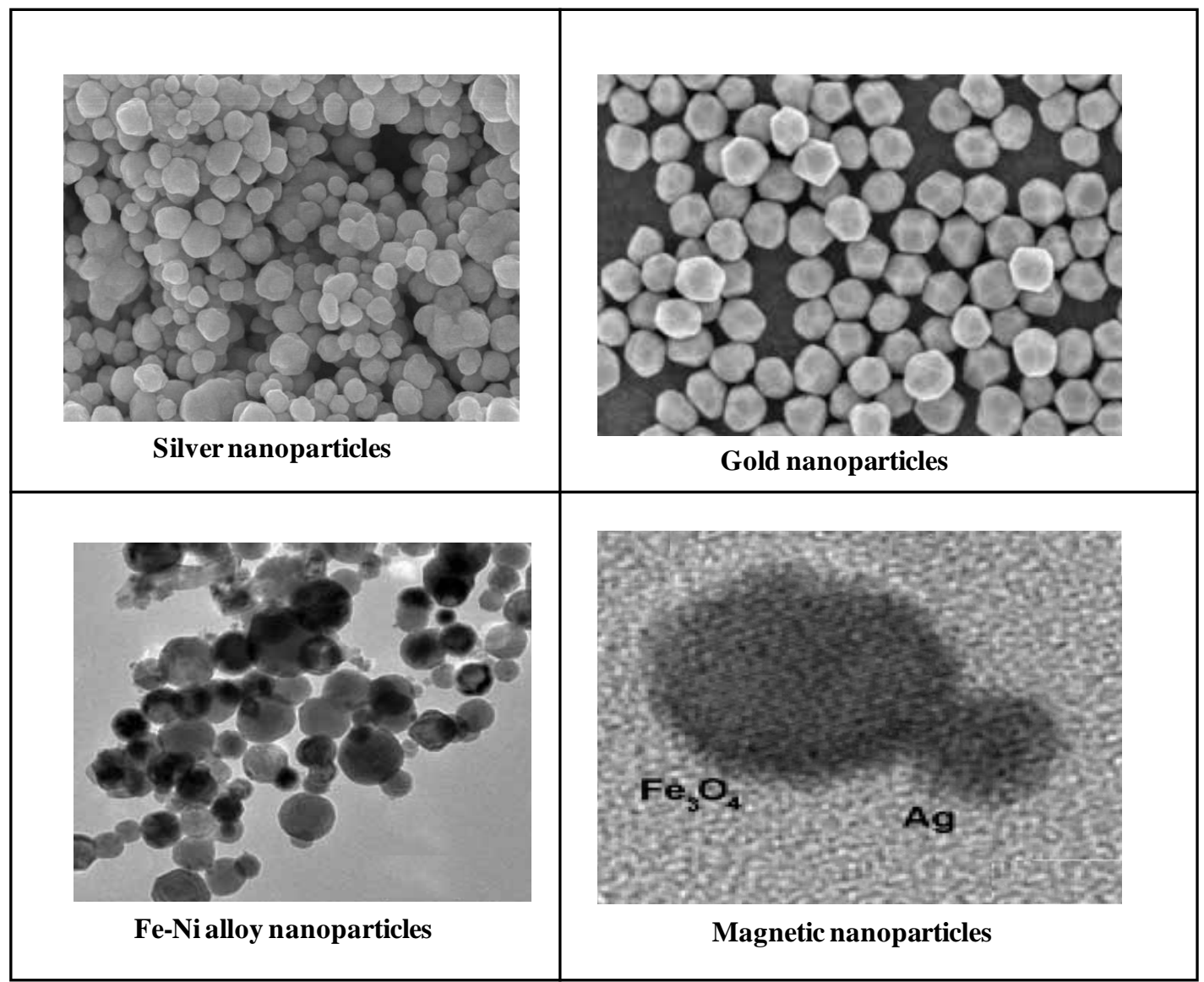

Figure 2: Types of nanoparticles.

\section{Methodology}

The information in this article was compiled from a variety of sources, including recent academic publications, a bibliographic database, and information from several government websites. The information was gathered from a variety of databases, including PubMed, PubMed Central, Science Direct, SCIELO, DOAJ, Science Alert, Semantic Scholar, and Google Scholar.

2.1 Unique features of nanoparticles (Khan et al., 2019)

1. Nanotechnology is used in the pharmaceutical industry in a variety of ways, including nanocrystals, liposomes, nanoparticleprotein conjugates, magnetic nanoparticles, nanogels, and biodegradable nanoparticles.

2. Due to the increased surface area in relation to volume, the behaviour of the atoms on the surface of the particles becomes more potent than that of the atoms inside the particles.

3. Nanoparticles do not impede light since their size is smaller than the order of wave length.

4. Because of the high surface-to-volume ratio, there is greater interaction between atoms in intermixed materials in nano particles, resulting in increased strength, heat resistance, lower melting point, and distinct magnetic characteristics of nano clusters.

5. Differences in the exposed surfaces of different nanoparticles of various shapes leads to differences in atomic distribution across the nanoparticle.
6. The zeta potential of maximum nanoparticles is varied from +30 and $-30 \mathrm{mv}$ and show high tendency to agglomerate to increase particles sizes except hydroxyl apatite.

2.2 Nanoparticles in relation to soil health

1. Nanoparticles can play an important role in characterization and improvement of soil physical properties.

2. Characterization of soil properties such as physical infrastructure of soil microaggregates of $10-50 \mu \mathrm{m}$ scale can be done by using nanoscale secondary ion mass spectroscopy and microscopy.

3. Natural organic matter in the soil or pore water has the ability to sorb, coat, and stabilise. The mobility, bioavailability, reactivity, and toxicity of nanoparticle suspensions are all affected.

4. Synthetic nanocomposite polymer clays have high water retention capacity and can be used to conserve soil moisture in arid soil.

5. Due to diffusion into microspores, structure rearrangement, and precipitation nature of compounds, soil nanoparticles show a rapid initial phase (milliseconds) followed by a sluggish phase (days) in sorption of heavy metals, metalloids, and organic pollutants. 


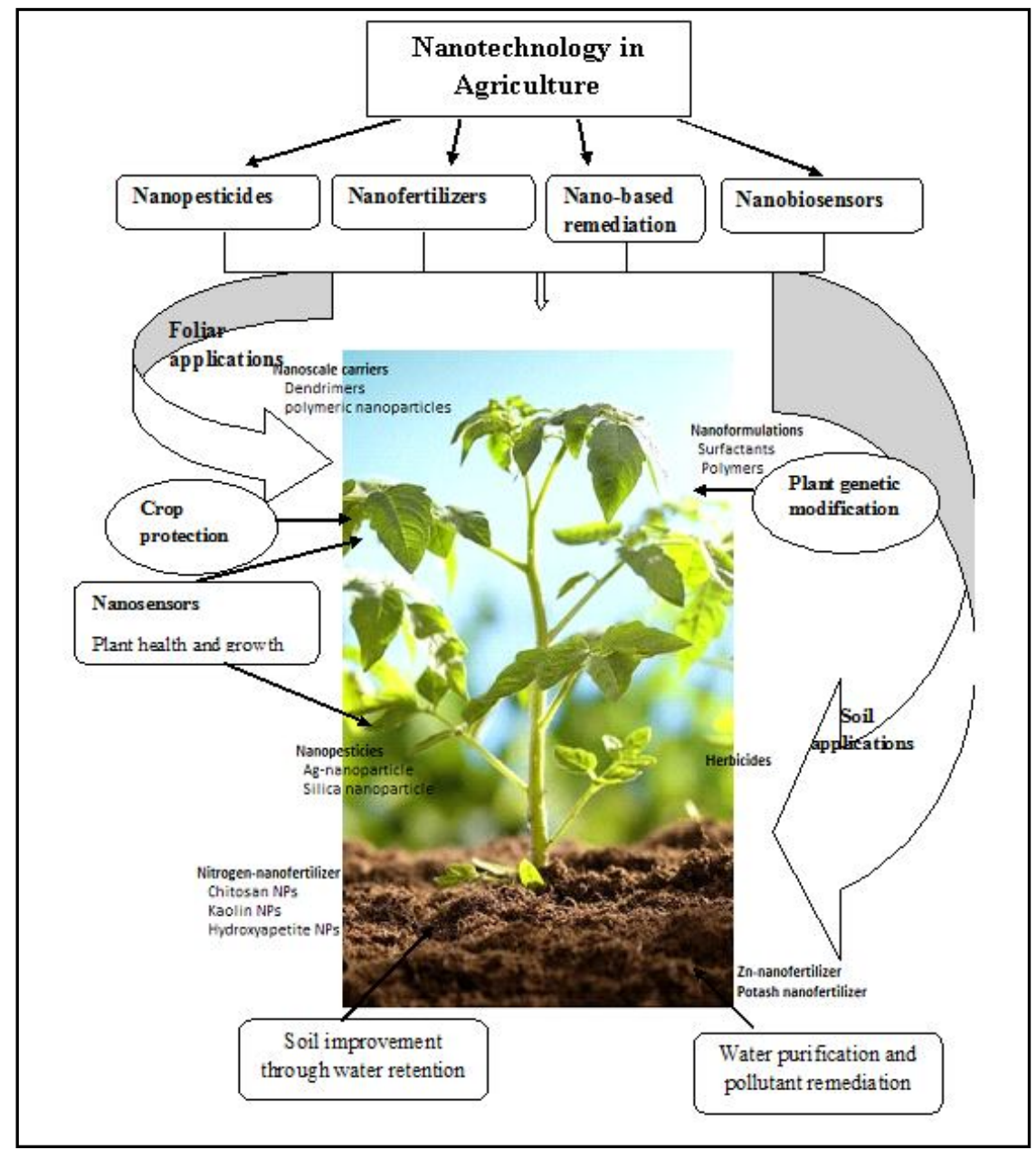

Figure 3: Applications of nanotechnology in MAPs.

\subsection{Nanofertilizers and nutrient use efficiency}

Nanofertilizers are nanoparticles that can directly increase the delivery of vital nutrients for plant growth, have a greater nutrient use efficiency, and can be given to a rhizosphere target (soil) or via foliar spray in a timely manner. Not only that, nanofertilizers help in improving imbalanced fertilization, depletion of soil organic matters, multinutrient deficiencies in MAPs, etc. As per the Indian Government data, the average utilization of fertilizers at around 500 lakh metric tonnes (LMT) in 2019-2020 and the same trend continued per year from last 10 years, but due to population growth, the demand for food is increased and side-by-side the application of the fertilizers are also enhanced. There are various types of nanofertilizers such as:

Slow release nano nitrogen fertilizer: The slow and continuous release of nitrogen is caused by nano zeolite impregnated with urea. $\mathrm{NH}^{+}$ions inhabiting the internal channels of zeolite progressively set free $\mathrm{N}$, allowing progressive absorption by medicinal plants.

Slow release nano phosphate fertilizer: Surface modified zeolite (SMZ) has been discovered to be a good sorbent for $\mathrm{PO}_{4}^{-3}$, allowing for a gradual release of P. (Giroto et al., 2017).
Uptake of nano micronutrients: When compared to regular zinc sulphate, application of $\mathrm{Zn}$ nanoparticles $(100 \mathrm{~nm})$ at a lower dosage $(0.28 \mathrm{ppm})$ improved maize plant development $(0.5 \mathrm{ppm})$. With the application of zinc oxide nanoparticles, plant height, root growth and volume, and dry matter weight can all be improved.

Based on the structure, nanofertilizers are nano porus zeolite, carbon nanotubes, boron nanofertilizer, zinc nanofertilizer, nanoherbicide, nanopesticide, nanofungicide, nanoaptamers. Nanoporus zeolites are the crystal form of aluminosilicate oxides, are widely used in catalysis and adsorption. Carbon nanotubes are cylindrical molecules with single-layer carbon atoms coiled up into sheets that increased the yield of MAPs. Boron and zinc nanofertilisers are the most fascinating nanofertilisers since they improved MAP output and quality. Herbicides are generally helps in weed controlling in MAPs but nano formulated herbicides are more effective formulation in sustained controlling of weeds with less quantity of applied herbicides. They are timed release and also have release linked to an environmental trigger. Not only nanoherbicides, but also nanopesticides are also helps in controlling detrimental pests in the initial stages of plant growth. They have better permeability, biodegradable, effective 
control in longer period, and also decrease pest density in below the economic threshold level. Both nanoherbicides, nanopesticides are applied in the form of nanocapsules, nanoemulsions, nanoparticles, etc. Thereafter, aptamers are short oligonucleotides that capable of specific binding to target with high affinity and widely applied in targeted nanodelivery systems. DNA aptamers are ideal nanobiosensors in MAPs because they target chemical interactions between the root system and soil bacteria and aid in the identification of accurate specific chemical signals between the soil microbes and plant rhizosphere.

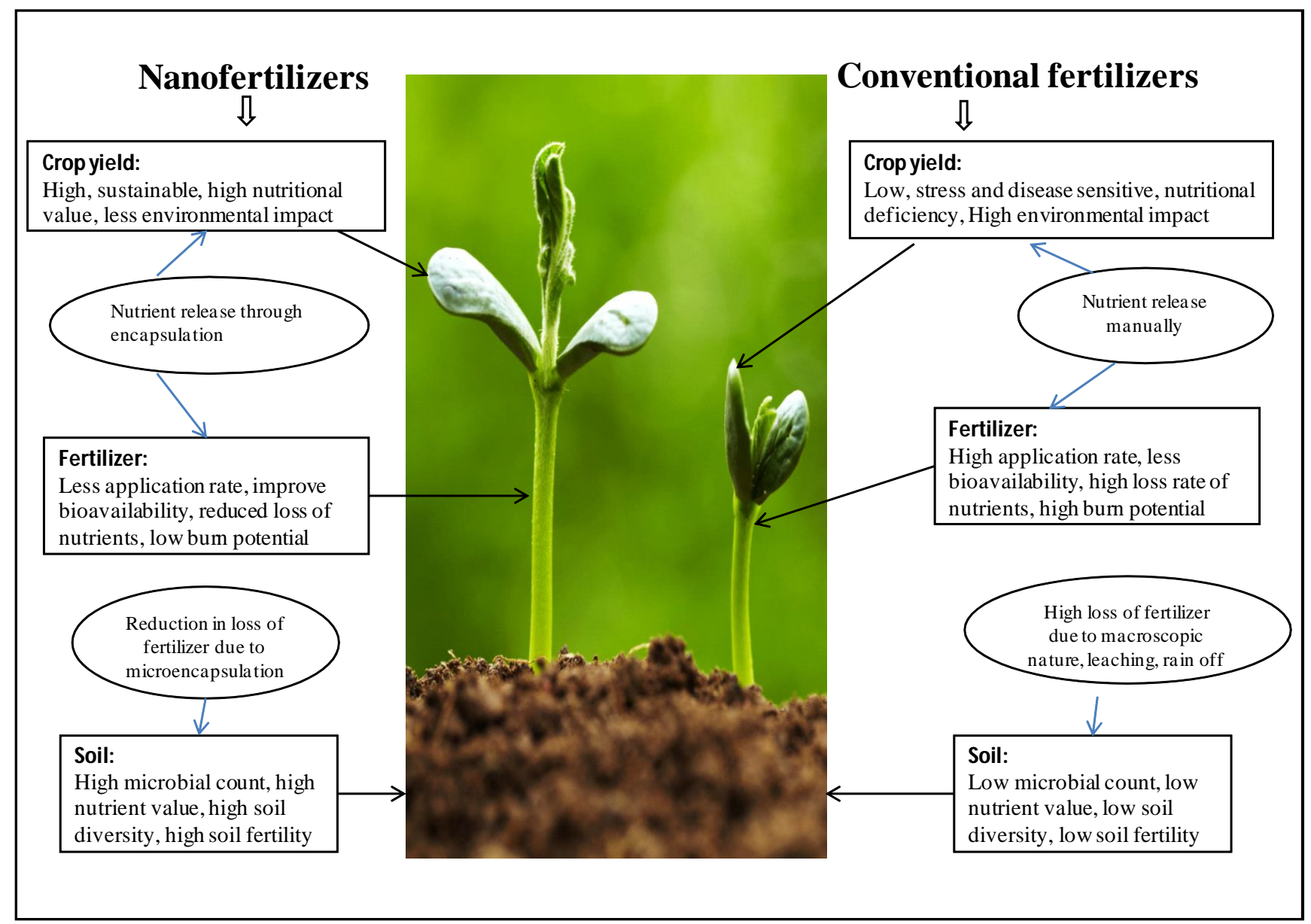

Figure 4: Some important difference between nanofertilizers and conventional fertilizers.

\subsection{Nanotechnology in MAPs}

Nanoformulation with polysaccharides and triterpenes from Ganoderma spp. are showed an effective on antitumor, enhancing immunity and protecting liver and reducing blood pressure and triglycerides, respectively. Nanoliposome from Antrodia cinnamomea also showed effective for antietching, liver protecting, analgesic, and relief from alcohol hangovers. Preliminary results from experiments with nanoversions of turmeric, black pepper, berberine, trifla, black seed, and other herbs show that the concept of improved efficacy in reduction in these herbal preparations can be proven. In medicinal plant, Stevia rebaudiana, the main active principle stevioside is formed in nanosize. PEG-PLA nanoparticles of size $150-170 \mathrm{~nm}$ is nano-bioconjugated for stevioside that showed the initial burst phase, followed by the slow controlled release of $2 \mathrm{~h}$ and 21 days, respectively which is helped for development of antidiabetic nano medicine (Yadav et al., 2011). The new revolutionary solution uses mesoporous nanoparticles, which inject the gene and activate it at the same time, in a precise and regulated manner, with no hazardous side effects. Cassia twigs, licorice root, and sealwort use nanotechnology to shrink the size of their active substances, allowing them to access malignant cells without harming healthy ones. The multi-walled carbon nanotubes are used to develop seed germination of tomato species (Solanum lycopersicum) (Khodakovskaya et al., 2009). In Spinacia oleracea, $\mathrm{TiO}_{2}$ nanoparticles increased dry weight by 73 per cent, photosynthetic rate by multiple times, and chlorophyll content by 45 per cent (Lei et al., 2007). On Brassica juncea, foliar spraying with gold nanoparticles increased stem diameter, plant height, number of pods, number of branches, and seed output compared to the control (Arora et al., 2012). By the application of $\mathrm{SiO}_{2}$ nanoparticles in Carthamus tinctorius plant, enhanced the total biomass yield in terms of canopy spread, stem diameter, plant height, and the number of achenes in capitulum extensively (Janmohammadi et al., 2016). Thereafter, liposome based nanoparticles of green tea, Aloe vera is effective for efficient antioxidant properties. Various nanometals such as silicon ( $\mathrm{Si}$ ), 
palladium $(\mathrm{Pd})$, gold $(\mathrm{Au})$, and copper $(\mathrm{Cu})$ showed the impact in seed germination of Lactuca sativa (Sadique et al., 2017). Likewise, $\mathrm{ZnO}$ and $\mathrm{CeO}_{2}$ nanoparticles increased fruit quality, starch content in Cucumber (Cucumis sativus) at concentration of 400 ppm (Zhao et al., 2014).

\section{Conclusion}

Nanotechnology's application in herbal medicine and soil science is still in its early stages of development, and there are significant gaps in our understanding of the issue. Perhaps, application of nanotechnology in agriculture is a significant characteristic in releasing agrochemical such as, supply of macronutrients and micronutrients to the plants for healthy development. As such, fertilization helps in improvement in nutrient uptake efficiency as well minimize the soil contamination. Nanofertilizers show controlled release of agrochemicals through specific targeted site, toxicity reduction, and also increased content of nutrient utilization by the released fertilizers. Thereafter, they transform poorly soluble and poorly absorbed physiologically active compounds into promising deliverable molecules. Furthermore, multidisciplinary efforts are needed for successful utilization of the modern technology to have rewarding future of great social relevance.

\section{Conflict of interest}

The author declares that there are no conflicts of interest relevant to this article.

\section{References}

Ahmad, N.; Sharma, S.; Singh, V.N.; Shamsi, S.F.; Fatma, A. and Mehta, B.R (2011). Biosynthesis of silver nanoparticles from Desmodium triflorum : A novel approach towards weed utilization, Biotechnol. Res. Int., 454090(1-8).

Arora, S.; Sharma, P.; Kumar, S.; Nayan, R.; Khanna, P. and Zaidi. M. (2012). Gold-nanoparticle induced enhancement in growth and seed yield of Brassica juncea. Plant Growth Regulation, 66(3):303-310.

Bayda, S.; Adeel, M.; Tuccinardi, T.; Cordani, M. and Rizzolio, F. (2019). The history of nanoscience and nanotechnology: From chemicalphysical applications to nanomedicine. Molecules, 25(1):112.

Das, D.K. (2005). Molecular soil science research and nanotechnology in agriculture. $4^{\text {th }}$ Prof. S. K. Mukherjee Commemoration Lecture. $92^{\text {nd }}$ Indian Science Congress, Nirma University of Science and Technology, Ahmedabad, January 3-7.

Fan, T.X.; Chow, S.K. and Zhang, D. (2009). Biomorphic mineralization: from biology to materials. Progress in Materials Science. 54(5):542659.

Fernández-Luqueño, F.; López-Valdez, F.; Valerio-Rodríguez, M.; Pariona,N.; HernándezLópez, J.; García-Ortíz, I.; López-Baltazar, J.; Vega-Sánchez, M.; Espinosa-Zapata, R. and Acosta Gallegos, J. (2014). Effects of nanofertilizers on plant growth and development, and their interrelationship with the environmental. Fertilizers: components, uses in agriculture and environmental impact. NOVA Science, New York. 211-224.
Giroto, A.; Guimarães, G.; Foschini, M. and Ribeiro, C. (2017). Role of slowrelease nanocomposite fertilizers on nitrogen and phosphate availability in Soil. Sci. Rep., 7:46032. https://doi.org/10.1038/ srep46032.

Hasan, S. (2015). A review on nanoparticles: Their synthesis and types. Research Journal of Recent Sciences, 4:1-3.

Janmohammadi, M.; Amanzadeh, T.; Sabaghnia, N. and Ion, V. (2016). Effect of nano-silicon foliar application on safflower growth under organic and inorganic fertilizer regimes. Botanica Lithuanica, 22(1):53-64

Kalia, A. and Kaur, H. (2019). Nanobiofertilizers: Harnessing dual benefits of nanonutrient and biofertilizers for enhanced nutrient use efficiency and sustainable productivity. In: Pudake R., Chauhan N., Kole C. (eds) Nanoscience for Sustainable Agriculture. Springer, Cham. pp:51-73. https://doi.org/10.1007/ 978-3-319-97852-9_3

Khan, I.; Saeed, K. and Khan, I. (2019). Nanoparticles: Properties, applications and toxicities. Arabian Journal of Chemistry, 12(7): 908-931.

Khodakovskaya, M.; Dervishi, E.; Mahmood, M.; Xu, Y.; Li, Z.; Watanabe, F. and Biris, A.S. (2009). Carbon nanotubes are able to penetrate plant seed coat and dramatically affect seed germination and plant growth. ACS Nano, 3(10):3221-3227.

Konishi, Y. and Uruga, T. (2007). Bioreductive deposition of platinum nanoparticles on the Bacterium Shewanella algae, J. Biotechnol., 128:648-653.

Lei, Z.; Mingyu, S.; Chao, L.; Liang, C.; Hao, H.; Xiao, W.; Xiaoqing, L.; Fan, Y.; Fengqing, G. and Fashui, H. (2007). Effects of nanoanatase $\mathrm{TiO}_{2}$ on photosynthesis of spinach chloroplasts under different light illumination. Biological Trace Element Research, 119(1):68-76.

Liu, R. and Lal, R. (2015). Potentials of engineered nanoparticles as fertilizers for increasing agronomic productions. Science of the Total Environment, 514:131-139.

Mukhopadhyay, S.S.; Prasad, V.R. and Gill, I.S. (2009). Nanoscience and Nanotechnology: Cracking prodigal farming. Nature Proceedings: hdl: 10101/npre. 2009.3203.1: Posted on April 29, 2009.

Mukhopadhyay, S. S. (2014). Nanotechnology in agriculture: Prospects and constraints. nanotechnol. Sci. Appl., 7:63-71.

Rai, M.; Yadav, A. and Gade, A. (2009). Silver nanoparticles as a new generation of antimicrobials. Biotechnol. Adv., 27(1):76-83.

Savci, S. (2012). An agricultural pollutant: Chemical fertilizer. International Journal of Environmental Science and Development, 3(1):73.

Sadique, S.; Nisar, S.; Dharmadasa, R.M. and Jilani, M.I. (2017). Effect of nanofertilizer and growth hormones on different plants. Int. J. Chem. Biochem. Sci., 11:113-119.

Tomar, A. and Garg, G. (2013). Short Review on application of gold nanoparticles. Global Journal of Pharmacology, 7(1):34-38.

Yadav, S.C.; Yadav, S.K.; Sood,A.; Sharma, M. and Singh, B. (2011). Development of antidiabetic nanomedicine from stevioside. J. Biomed. Nanotechnol., 7(1):54-55.

Zhao, L.; Peralta-Videa, J.R.; Rico, C.M.; Hernandez-Viezcas, J.A.; Sun, Y.; Niu, G.; Servin, A.; Nunez, J.E.; Duarte-Gardea, M. and Gardea-Torresdey. J.L. (2014). $\mathrm{CeO}_{2}$ and $\mathrm{ZnO}$ nanoparticles change the nutritional qualities of cucumber (Cucumis sativus). Journal of Agricultural and Food Chemistry. 62(13):2752-2759. 